\title{
Informatics as a Fundamental Discipline in General Education: The Danish Perspective
}

\author{
Michael E. Caspersen
}

\begin{abstract}
Informatics in general, and the particular development of artificial intelligence, is changing human knowledge, perception, and reality, thus radically changing the course of human history. Informatics has made it possible to automate an extraordinary range of tasks by enabling machines to play an increasingly decisive role in drawing conclusions from data and then taking action. The growing transfer of judgment from human beings to machines denotes the revolutionary aspect of informatics.

For societies to maintain or regain democratic control and supremacy over digital technology, it is imperative to include informatics in general education with a dual perspective on possibilities and implications of computing for individuals and society. The Danish informatics curriculum for general education acknowledges the dual and bipartite nature of informatics by complementing a constructive approach to computing with a critical analytic approach to digital artifacts.
\end{abstract}

\section{Digital Humanism and General Informatics Education}

Information technology is a technology unlike any other humankind has invented. All other technologies stretch our physical ability by enabling us to move faster from one place to another, to generate (green) energy, to develop life-saving medicine, to refine food production, and so forth. Information technology is crucial for other modern technologies, but the essential unique quality of information technology is that it stretches our cognitive ability.

Already in 1967, Danish Turing Laureate Peter Naur wrote about the importance of including informatics in general education (Naur, 1967, pp. 14-15; Naur 1992, p. 176):

\footnotetext{
M. E. Caspersen ( $\square)$

Aarhus, Denmark

e-mail: mec@it-vest.dk

It-vest - Networking Universities, Department of Computer Science, Aarhus University, 
To conceive the proper place of informatics in the curriculum, it is natural to compare with subjects of similar character. One will then realise, that languages and mathematics are the closest analogies. Common for the three is also their character as tools for many other subjects.

Once informatics has become well established in general education, the mystery surrounding computers in many people's perceptions will vanish. This must be regarded as perhaps the most important reason for promoting the understanding of informatics. This is a necessary condition for humankind's supremacy over computers and for ensuring that their use do not become a matter for a small group of experts, but become a usual democratic matter, and thus through the democratic system will lie where it should, with all of us.

Naur's plea to properly include informatics in general education with a standing similar to languages and mathematics and his arguments for the plea are not less relevant today, more than half a century after their articulation.

In June 2018, The Atlantic brought the chronicle How the Enlightenment Ends by Henry Kissinger (2018); in here, the author writes:

Heretofore, the technological advance that most altered the course of modern history was the invention of the printing press in the 15th century, which allowed the search for empirical knowledge to supplant liturgical doctrine, and the Age of Reason to gradually supersede the Age of Religion. Individual insight and scientific knowledge replaced faith as the principal criterion of human consciousness. Information was stored and systematized in expanding libraries. The Age of Reason originated the thoughts and actions that shaped the contemporary world order.

But that order is now in upheaval amid a new, even more sweeping technological revolution whose consequences we have failed to fully reckon with, and whose culmination may be a world relying on machines powered by data and algorithms and ungoverned by ethical or philosophical norms.

Informatics in general, and the particular development of artificial intelligence (AI), is changing human knowledge, perception, and reality - and, in so doing, changing the course of human history. Informatics has made it possible to automate an extraordinary range of tasks and has done so by enabling machines to play a role an increasingly decisive role - in drawing conclusions from data and then taking action. The growing transfer of judgment from human beings to machines denotes the revolutionary aspect of informatics and of AI as described by Kissinger in the aforementioned chronicle.

More than half a century after Naur's plea, informatics is finally becoming a school subject. Internationally there is a quite fast emerging breeze in the direction of making informatics part of national curricula and part of general education for all. This trend reflects the growing recognition that informatics is an important foundational competence along with "the three Rs": reading, writing, and arithmetic/ mathematics.

However, informatics curricula in general tend to prioritize technical content (computing systems, networks and the Internet, data and analysis, algorithms and programming) - perhaps adding an element of impact of computing.

The Danish curriculum for general education (one for upper secondary and a more novel for primary and lower secondary) acknowledges the bipartite nature of all computations directed at purposes in the real world - the problem domain and the 


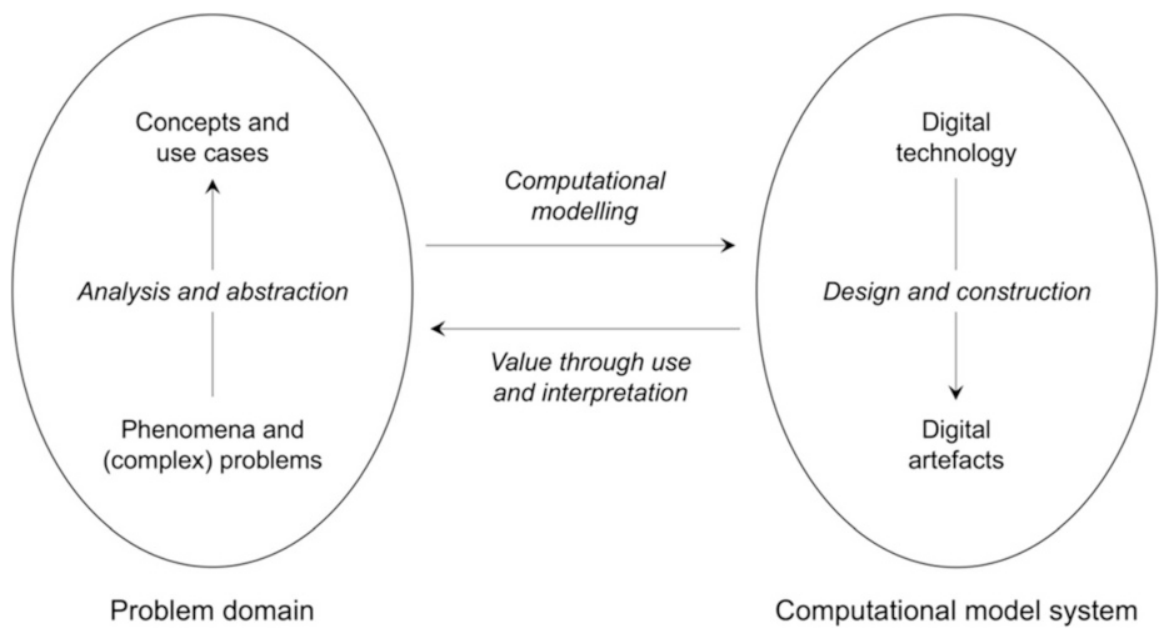

Fig. 1 The bipartite nature of computing

computational model system - as well as the relation between the two: representation and interpretation (see Fig. 1).

The equal inclusion of problem domain and interpretation, complementing computational model system and representation, is rather unique and embodies the Danish curriculum's perspective on digital humanism.

\section{Political Emphasis on Informatics Education for All}

In 2016, former president Obama launched CS for All as a bold new initiative to empower all American students from kindergarten through high school to learn computer science and be equipped with the computational thinking skills they need to be creators in the digital economy, not just consumers, and to be active citizens in our technology-driven world (White House 2016).

In 2018, major European and international organizations formed the coalition Informatics for All (Informatics for All 2018). In many ways, the Informatics for All initiative mirrors Obama's CS for All initiative. A crucial element of the European approach, which distinguishes it from the CS for All initiative, is the two-tier strategy at all educational levels: informatics as a discrete subject, that is, a fundamental and independent subject in school (like language and mathematics), and the integration and application of informatics with other school subjects, as well as with study programs in higher education. Perhaps overly simplified, the two tiers may be characterized as Learn to Compute (discrete subject) and Compute to Learn (integration); see Caspersen et al. (2019). 
In 2020, the EU Commission launched Digital Education Action Plan for 2021-2027, which mentions informatics as a priority area and action (European Commission 2020a, p. 9):

To support a high-performing digital education ecosystem, the European Commission will pursue the following actions: [...]

10. Propose a Council recommendation on improving the provision of digital skills in education and training [...] through a focus on inclusive high-quality computing education (informatics) at all levels of education.

The EU Commission highlights informatics education as a tool to boost digital competence (European Commission 2020b, p. 47):

Informatics education in school allows young people to gain a critical and hands-on understanding of the digital world. If taught from the early stages, it can complement digital literacy interventions. The benefits are societal (young people should be creators not just passive users of technology), economic (digital skills are needed in sectors of the economy to drive growth and innovation) and pedagogical (computing, informatics and technology education is a vehicle for learning not just technical skills but key skills such as critical thinking, problem solving, collaboration and creativity).

In most European countries, the ambition is not yet as high as it ought to be considering the impact that the digital revolution has had on all aspects of society (CECE 2017; CECE's map 2017), and therefore the European Commission's emphasis on inclusive informatics education at all levels of education is both important, necessary, and timely.

\section{The Danish Informatics Curriculum for General Education}

Various flavors of informatics have been a topic in Danish upper secondary schools for more than 50 years (Caspersen and Nowack 2013).

In late 2008, the Ministry of Education established a task force to conduct an analysis of informatics in upper secondary schools and provide recommendations for a revitalization of the subject, not as a niche specialty but as a general subject relevant for all. Subsequently, a new general, coherent, and uniform informatics subject was developed, tested, and finally made permanent in 2016, however, not yet as a compulsory subject for all upper secondary education.

A distinct aspect of the Danish informatics curriculum is the focus on digital empowerment. We define digital empowerment as a concern for how students, as individuals and groups, develop the capacity to understand digital technology and its effect on their lives and society at large and their ability to engage critically and curiously with the construction and deconstruction of digital artifacts (Dindler et al. 2021).

An approach to embrace digital empowerment was present already in the Danish upper secondary informatics curriculum developed in 2009 (Caspersen 2009). One 


\begin{tabular}{|c|c|}
\hline 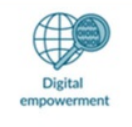 & $\begin{array}{l}\text { Digital empowerment } \\
\text { Critical, reflexive and constructive examination and understanding of possibilities and } \\
\text { consequences of digital artefacts. } \\
\text { Analysis of technology-intention and use | Evaluation | Reframing/redesign }\end{array}$ \\
\hline Digital design and & $\begin{array}{l}\text { Digital design and design processes } \\
\text { Organisation and implementation of iterative and incremental design processes } \\
\text { considering the context of future use. } \\
\text { Problem framing | Ideation | Prototyping | Argumentation }\end{array}$ \\
\hline 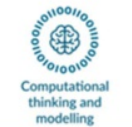 & $\begin{array}{l}\text { Computational thinking and modelling } \\
\text { Analysis, modelling and structuring of data and data processes for } \\
\text { automatic processing by a computer. } \\
\text { Data | Algorithms | Structuring | Modelling }\end{array}$ \\
\hline$\underbrace{(\infty, 1)}_{\substack{\text { Technological } \\
\text { knowledge and skills }}}$ & $\begin{array}{l}\text { Technological knowledge and skills } \\
\text { "Mastery" of digital technologies (computer systems and networks), } \\
\text { associated languages and programming. } \\
\text { Programming | Computer systems | Network | Security }\end{array}$ \\
\hline
\end{tabular}

Fig. 2 The four competence areas in the Danish informatics curriculum for primary and lower secondary school

of the six key competence areas was Use and impact of digital artifacts on human activity. The purpose of this competence area was that students should understand that digital artifacts and their design have a profound impact on people, organizations, and social systems. Design of a system is not just design of the digital artifact and its interface, it is also design of the use and workflow that unfolds around the artifact. The purpose is that the students understand the interplay between the design of a digital artifact and the behavioral patterns that intentionally or unintentionally unfolds (Caspersen and Nowack 2013).

The informatics curriculum for primary and lower secondary education was developed by mandate of the Danish Ministry of Education in 2018 and is running on trial until 2021 in about $5 \%$ of primary and lower secondary schools across Denmark.

The author of this chapter and a colleague from the Department of Digital Design and Information Studies at Faculty of Arts were invited to serve as chairs for the group developing the curriculum. In choice of chairs, the Minister of Education signaled the importance of integrating a digital humanism perspective in the design of the curriculum.

The informatics curriculum for primary and lower secondary school consists of four competence areas (Danish Ministry of Education 2018):

- Digital empowerment

- Digital design and design processes

- Computational thinking and modeling

- Technological knowledge and skills

An overview of the four competence areas is provided in Fig. 2. 
Digital empowerment refers to the critical and constructive exploration and analysis of how technology is imbued with values and intentions and how it shapes our lives as individuals, groups, and as a society. It is concerned with the ethics of digital artifacts and promotes an analytical and critical approach to digital transformation.

Digital design and design processes refers to the ability to frame problems within a complex problem area and, through iterative processes, generate new ideas that can be transformed into form and content in interactive prototypes. It focuses on the processes through which digital artifacts are created and the choices that designers have to make in these processes, highlighting students' ability to work reflectively with complex problems.

Computational thinking and modeling concerns the ability to translate a framed problem into a possible computational solution. It focuses on students' ability to analyze, model, and structure data and data processes in terms of abstract models (e.g., algorithms, data models, and interaction models).

Technological knowledge and skills concerns knowledge of computer systems, digital tools and associated languages, and programming. It focuses on the students' ability to express computational ideas and models in digital artifacts. This includes the ability to use computer systems and the language associated with these and to express ideas through programming. Working within this area aims at providing students with the experience and abilities needed to make informed choices about the use of digital tools and technologies.

Two of the competence areas - Computational thinking and modeling and Technological knowledge and skills - encompass classic computing subjects, while the two others are less standard in informatics curricula, if present at all.

\section{Digital Humanism in Informatics: The Danish Perspective}

The four competence areas constitute a holistic approach to informatics, here described in terms of the model in Fig. 1.

The real or an imaginary world is populated with phenomena and activities, which - through analysis and abstraction - can be understood in terms of concepts and use cases. Through computational modeling, these can be prioritized, structured, and modeled for computational representation. Through design and construction using digital technology, new digital artifacts can be developed to manipulate and transform these representations into something, which hopefully provides value through interpretation and use back in the real world (Madsen et al. 1993, chap. 18). The four competence areas map more or less one-to-one to the four processes in the model (Fig. 3).

Digital design and design processes covers primarily activities related to the problem domain. Computational thinking and modeling maps to the process going 


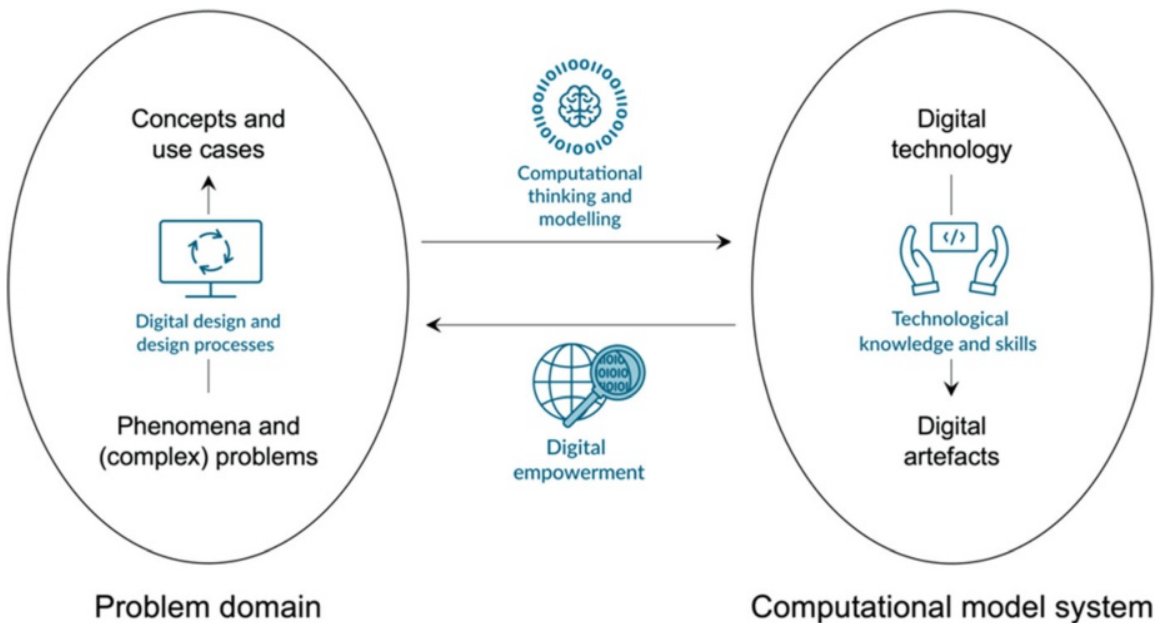

Fig. 3 Mapping of the four competence areas to the four processes in computational modeling of a problem domain

from problem domain to the computational model system. Technological knowledge and skills provides competences to design and construct digital artifacts. Digital empowerment relates to the process back from the computational model system to the problem domain.

Not only do the four competence areas constitute a nice, full circle. They also mutually strengthen each other. Analytic competences provided by digital empowerment will strengthen the three other competence areas. And vice versa: if you actually know how to build digital artifacts, your critical and constructive analysis can become much richer and deeper.

\section{The Bipartite Nature of Informatics}

The computational model system (computer systems, networks, security and programming languages, etc.) is a classic component for an informatics curriculum. No surprises here.

Inclusion of Digital design and design processes recognizes the bipartite nature of all computation that is directed at purposes in the real world. Thus, we embrace both problem domain and solution domain: the entire bipartite system - both the software machine and the physical (or imaginary) world whose behavior it governs.

This is not generally embraced in informatics curricula for general education. The focus on design process is inspired by the Scandinavian school of Participatory Design, which originated in the 1970s with subsequent development and proliferation beyond Scandinavia (Greenbeaum and Kyng 1991). It is also inspired by Donald Schön's philosophy of design as a reflective practice from the $1980 \mathrm{~s}$ 
(Schön 1983). The particular notion of problem framing and reframing are essential parts of this and is also inspired by the seminal work of British computer scientist Michael Jackson in the 1990s (Jackson 2000).

However, the focus is not only on the two parts of "the bipartite system" problem domain and solution domain - but also on the relations between the two parts: representation and interpretation.

\section{Embracing Uncertainty: The Representational and the Interpretational Challenge}

Most aspects of the physical world, which we attempt to capture and represent in computational models and artifacts, are blurred, uncertain, and nondeterministic.

On the other hand, the computational models we construct are fundamentally strict, certain, and deterministic.

The challenge has two faces. One is the representational challenge: How can we model the blurred, uncertain, and nondeterministic aspects of the world in computational artifacts?

The other is the interpretational challenge: How do we avoid to constrain and eventually dehumanize our understanding of phenomena and concepts in the real world when our worldview is increasingly defined through the lenses of strict, certain, and deterministic computational models and artifacts?

The representational challenge is addressed by the competence area Computational thinking and modeling (data, algorithms, structuring, etc.), which is again a self-evident component in an informatics curriculum.

The interpretational challenge is addressed by the competence area Digital empowerment, which represents the ability to analyze and evaluate digital artifacts with a focus on intention and use through a critical, reflexive, and constructive examination and understanding of consequences and possibilities of a digital artifact. This competence area is for digital artifacts what literature analysis is for novels, but with the additional liberating component of reframing and redesign - realizing that digital artifacts are human-made and could have been designed differently if other perspectives had been applied.

\section{Conclusions}

We have presented elements of the current international development regarding informatics in general education for all, and we have presented the current development in Denmark in upper secondary school and more recently in primary and lower secondary school. 
We have presented the distinct Danish perspective on digital humanism represented by an approach to informatics in school where the four competence areas of the curriculum constitute a holistic approach recognizing the bipartite nature of all computation by addressing problem domain as well as solution domain - but also the relations between the two: representation and interpretation.

In doing so, we aim at addressing two particular concerns related to computational artifacts:

1. How can we meaningful model the blurred, uncertain, and non-deterministic aspects of the world in computational artifacts?

2. How do we avoid to constrain and eventually dehumanize our understanding of phenomena and concepts in the real world when our worldview is increasingly defined through the lenses of strict, certain, and deterministic computational models and artifacts?

These are essential issues on our way forward into an in all aspects increasingly digital society. It is imperative that informatics become a fundamental and general discipline in school in order to ensure that future generations become educated and empowered to contribute to the development of their digital environment and to realize our technological advancement to ensure the evolution of a safe, secure, environmentally conscious and just society.

Acknowledgment I would like to thank the anonymous reviewers for valuable feedback to an earlier version of the manuscript.

\section{References}

Caspersen, M.E. (2009). Kernekompetencer i informationsteknologi (in Danish). Notes for ministerial working group. Accessed 21st April 2021.

Caspersen, M.E. \& Nowack, P. (2013). Computational Thinking and Practice - A Generic Approach to Computing in Danish High Schools, Proceedings of the 15th Australasian Computing Education Conference, ACE 2013, Adelaide, South Australia, Australia, pp. 137-143.

Caspersen, M.E., Gal-Ezer, J., McGettrick, A.D. \& Nardeli, E. (2019). Informatics as a Fundamental Discipline for the 21st Century. Communications of the ACM 62 (4), DOI:https:// doi.org/10.1145/3310330.

CECE (2017). Informatics Education in Europe: Are We All In The Same Boat?, Report by the Committee on European Computing Education, Informatics Europe and ACM Europe. Accessed 12th March 2021.

CECE's Map (2017). CECE's Map of Informatics in European Schools, ACM Europe and Informatics Europe. Accessed 12th March 2021.

Danish Ministry of Education (2018). Indholdet i forsøgsfaget teknologiforståelse (in Danish). The Danish Ministry of Education. Accessed 14th March 2021.

Dindler, C., Iversen, O.S., Caspersen, M.E. \& Smith, R.C. (2021). Computational Empowerment. In Computational Thinking Education in K-12: Artificial Intelligence Literacy and Physical Computing, MIT Press, 2021. Eds. Kong, S-C \& Abelson, H. Scheduled for publishing in spring 2021. 
Greenbeaum, J. \& Kyng, M., Eds. (1991). Design at Work: Cooperative Design of Computer Systems. CRC Press.

European Commission (2020a). Digital Education Action Plan (2021-2027) - Resetting education and training for the digital age. European Commission. Accessed 12th March 2021.

European Commission (2020b). Commission Staff Working Document. European Commission. Accessed 12th March 2021.

Informatics for All (2018). Informatics for All. Accessed 12th March 2021.

Jackson, M. (2000). Problem Frames: Analyzing and structuring software development problems. Addison-Wesley.

Kissinger, H. (2018). How the Enlightenment Ends. The Atlantic, June 2018. Accessed 21st April 2021.

Madsen, O.L., Møller-Pedersen, B. \& Nygaard, K. (1993). Object-Oriented Programming in the BETA Programming Language. Addison-Wesley.

Naur, P. (1967). Datalogi - læren om data (in Danish). The second of five Rosenkjær Lectures in Danish Broadcasting Corporation 1966-67 published as Datamaskinerne og samfundet, Munksgaard. Accessed 21st April 2021.

Naur. P. (1992). Computing: A Human Activity, ACM Press.

Schön D.A. (1983). The Reflective Practitioner: How professionals think in action. Temple Smith. White House (2016). Computer Science For All. The White House. Accessed 12th March 2021.

Open Access This chapter is licensed under the terms of the Creative Commons Attribution 4.0 International License (http://creativecommons.org/licenses/by/4.0/), which permits use, sharing, adaptation, distribution and reproduction in any medium or format, as long as you give appropriate credit to the original author(s) and the source, provide a link to the Creative Commons license and indicate if changes were made.

The images or other third party material in this chapter are included in the chapter's Creative Commons license, unless indicated otherwise in a credit line to the material. If material is not included in the chapter's Creative Commons license and your intended use is not permitted by statutory regulation or exceeds the permitted use, you will need to obtain permission directly from the copyright holder.

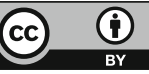

